\title{
Examining a PhD Thesis:
}

\section{Lessons Learned?}

\author{
Azham Md. Ali (Corresponding author) \\ Department of Accounting and Finance \\ Faculty of Management and Economics \\ Universiti Pendidikan Sultan Idris \\ 35900 Tanjong Malim Perak
}

Tel: 605450 6500, Fax: 605459 4642, e-mail: azham @fpe.upsi.edu.my

\author{
Hamidah Yusof \\ Department of Management and Leadership \\ Faculty of Management and Economics \\ Universiti Pendidikan Sultan Idris \\ 35900 Tanjong Malim Perak
}

Received: January 10, 2012 Accepted: March 02, 2012 DOI: 10.5296/ijafr.v2i1.1486

\begin{abstract}
A recent experience in being an external examiner for a $\mathrm{PhD}$ thesis was a most distressful experience which went on for a period of several months covering four distinct phases: pre exam, written exam, oral exam and post viva. This paper focuses on the findings of the written exam phase. It is also concerned with the various benchmarks that examiners may use in judging the quality of a $\mathrm{PhD}$ thesis. These standards are extracted from 17 web sources chosen from among several hundred websites of reputable overseas institutions. All this and more were earlier covered in the fifty plus pages of a single space thesis examining report completed prior to the oral exam. Interested parties may learn several valuable lessons from this experience. This could perhaps help to ensure the Malaysian hope to be a center of excellence in higher education shall come true sooner rather than later.
\end{abstract}

Keywords: $\mathrm{PhD}$ thesis, external examiner's report, writing standards 


\section{Introduction}

Horror is the right word to describe my experience in going through the thesis ... The most painful and stressful experience in reading the thesis had also blended with anger (which came out very well to the surface from time to time in the form of venomous words) for finding a $\mathrm{PhD}$ that is so awful in so many ways - and for the fact that it is none other than me (who is ever so conscious of producing the best writing piece he possibly could every time) who is saddled with the task of being its external examiner! ... All in all, the student deserves the grade F. He has failed the PhD. But I can live with the fact that he is given another chance.

In order to be successful, one is normally told that he or she merely needs to learn from those who have made it. But, in some instances, several good lessons could perhaps be learned from among those who fail to make it in the sense that those who come later should try their best to avoid making the same mistakes. One of these instances is concerned with a student doing a $\mathrm{PhD}$ at a local university whose thesis was recently examined. To see how bad the thesis is, check out the quotation above which appeared on the very first page of the fifty plus single space examination report.

How the thesis had actually come to be in this perilous state is not the concern of the paper. Instead, simply stated, the paper is concerned with a delineation of the various problems found in the thesis. Related to this, the paper is interested to lay bare the standards that a $\mathrm{PhD}$ thesis may be evaluated against. These standards come from several reputable overseas institutions. Local PhD granting institutions should perhaps emulate these institutions in order to raise the degree to a world class level - in deeds rather than in mere words.

In the delineation of the problems found in the thesis, it is notable that the following is implemented in order to minimize the risk of having readers able to identify the student and the institution which he or she studies in: a limited number of illustrations and as little elaboration as possible is provided. These illustrations and elaboration of the thesis' problems are pulled out from over 19,000 words or around 40 pages of the related section of the thesis examination report which is comprised of close to 27,000 words or over fifty pages of single space writing in total.

The paper continues next with a section on the problems found in the thesis. It is followed with the laying out of standards used in evaluating a $\mathrm{PhD}$ thesis coming from $16 \mathrm{PhD}$ granting institutions overseas plus one which is formed by a network of institutions of higher learning. Having stated the specific weaknesses and the international benchmarks, the paper comes to an end with a section on discussion and conclusions.

\section{The Myriad of Problems}

So, trust me on the following: until now I have never encountered a thesis like the present one which is marked with so many inadequacies. It is as if the thesis which utilizes the quantitative approach is not yet ready for submission. It is also as if the person producing it has the attitude of "can't be bothered" throughout the writing process. Hence, while reading it, I could not help myself from thinking that the thesis is probably a way for the student to pull 
down certain parties who he is not happy with! But I may be totally wrong in my estimation. The "can't be bothered" attitude is probably nothing more than a sickening attempt to portray the image of a brilliant scholar who has no need to abide with the rules of thesis writing and for that matter the everyday meaning of doing a $\mathrm{PhD}$ or scientific research!

These words which appeared on page four of the preamble section of the thesis examination report (from hereon it is represented by the acronym TER) are concerned with the very low writing quality found in the thesis (which I have never come across before in any other $\mathrm{PhD}$ theses) and the possible inappropriate motivations behind such effort. Later, on the very same page of the report, I had the following written to describe among others of what is generally wrong with the thesis:

In the very next section the details provided should provide the plain answer which is that it is funny (though I am not laughing!), it is fake, it is not logical, it is unbelievable, it is ... you've got the drift! ... I believe "atrocious" is the word people would use for this kind of writing. Almost all of the numerous unforgivable acts have so many examples to prove that there is here a substandard $\mathrm{PhD}$ thesis.

So, what exactly are the problems with the thesis? The simple answer is that there are of two types. Some are genuinely problems of writing while others appear to be more deep seated problems which concern the fundamental issues of a scholarly research such as research motivation and theoretical framework. And, what turns such a simple answer to a rather complicated one is the fact that it appears that in some cases the writing problems have emerged for perhaps no other reason than to camouflage the existence of these deep seated problems!

In the delineation of the thesis' problems that numbered to twelve next, it is perhaps worth noting that no attempt is made to divide them into genuine problems of writing or deep seated problems of scholarly research. This is because as far as the paper is concerned each single one of them is of equal importance in ascertaining a success or failure of a $\mathrm{PhD}$ thesis. It is also notable that in the delineation of the thesis' problems, the last four are concerned with the specific chapters of the thesis beginning with the chapter on theoretical framework. This is in contrast to the delineation of the first seven problems. In this latter case, each of the seven problems is not related to a chapter of the thesis but instead may be detected in every single chapter of the thesis - even though in most cases the illustrations or elaboration are limited to instances found in the first few pages of the thesis. That there is a close connection between the two sets of problems and for that matter amongst a number of the first seven problems discussed is made clear with the brief description provided under the eighth problem of lack of clarity in writing of several parts of the thesis.

\section{- Failing to be consistent}

$\checkmark$ In listing out the four research objectives in the first half of the page, there is different size of spacing use to separate them.

$\checkmark$ In the second to the last chapter, for the term percent in some places is replaced with the symbol $\%$. 
$\checkmark$ The bibliography where inconsistency is abound!

\section{- Incomprehensible English}

Down below page 5 of the TER, I began by saying the following:

There are several places in the abstract where even repeated reading on my part of the same words or sentences bring little comprehension!

Next, when it concerns the thesis' abstract alone, I came out with three examples of incomprehensible English including that which says: “... was consistent with the recommendations in the position paper..."

Following that example, I wrote among others the following:

Which position paper is the student referring to? Though one may get to know this later on after going through the thesis, an abstract of a written piece should have said something about which position paper it is referred to.

\section{- Failing to substantiate remarks made}

$\checkmark$ For the very last sentence on page 9 where it is mentioned the following: "All the relevant information ... and some of the statistical results are presented in the Appendices." Which statistical results and which appendices? I believe nobody knows what he was talking about since these statistical results appearing in some appendices are nowhere to be found!

$\checkmark$ The word "recently" is mentioned in the very first paragraph of the literature review on page 10 to refer to work on corporate governance. Next, in the very same paragraph, one may find however a number of not so recent studies: several papers were published in the mid 1990s and there is even one in 1980 !

At the end of the listing of several examples of the failure to substantiate remarks made found in the first several pages of the thesis, it is notable that $I$ have the following written on page 7 of the TER:

Frankly speaking, I am dead tired of this student acting like a magician in writing out this thesis of his. But the sleight of hands of a magician which the student has tried to mirror with his use of words in various sections of the thesis has failed to achieve its goals with me! I am far from being impressed. Instead, I have the urge to throw up my stomach's contents every time I come across this disgusting attempt of his!

\section{- Ideas flow horribly / lack of coherence}

The second paragraph from the top on page 14 has the following: "Sarens and Beelde (2006) ... to the assurance role. In fact, the internal auditors are expected ...." In using the phrase "in fact" right after the sentence which refers to the 2006 work, is the student referred to what was expected by the respondents of the 2006 study? Or, is he merely talking about some other parties' expectation of the auditors' role? It seems the latter is the case if one 
were to read the rest of the paragraph which happens to be the very last paragraph of the section 2.2. If that is the case, should not the paragraph be separated to two and that the use of the phrase "in fact" is to be avoided?

Following the listing of three examples including the above which appeared on the first few pages of the thesis, I have the following mentioned on page 8 of the TER:

Before I end this very section there is a need for me to point out that all those I have pointed out thus far reflecting the lack of coherence pale in comparison to the lacking in coherence due to the inclusion of the following research objective in the study...

I am not able to see how this one objective fits in with the three others... And as far as I am concerned in reading the thesis the student too has not shown any effort to fit in that objective with the other three. Instead, all the time I have got the feeling from his writing - in reading between the lines more than anything else - that it is almost the natural thing for him to have that objective to be aimed for together with the other three for the study. I am down right not convinced! For a resubmitted thesis, he and the people around him should look into this closely - or else be prepared for the examiner of that thesis to raise the matter as I do here. Is it possible that that objective is raised for reasons that have nothing to do with the need to have a coherent thesis? Whatever these reasons may be, I believe that the inclusion of that objective has hurt the thesis.

\section{- English goes haywire}

$\checkmark$ The second paragraph from the top on page 15 has the following: "In fact there are various examples relating the fact ..." Shouldn't it be "relating to the fact"? (By the way, the phrase "in fact" in that sentence should have been followed by a comma!)

$\checkmark$ The second paragraph for the section 2.4 on page 16 has the following: "This scenario is only one simple example how the management ..." Shouldn't it be "example of how"?

$\checkmark$ The first paragraph of section 2.3 on page 14 there is a line which has the symbol comma appear right after the word "in fact": "There are in fact, a list of roles and ..."

$\checkmark$ The second paragraph from below on page 17 has the following sentence which has several errors in the use of commas, etc.: "Although, the board has to face the situation of information symmetry with the management, the board in actual fact, has the opportunity to reduce the problem in both situations i.e., during the appointment of a candidate and in board meetings by utilizing ..."

\section{- Falsifying research findings of others}

I began my diatribe by saying the following on top of page 10 of the TER: 
In the very last paragraph on page 19 there is this line: "In addition, there are other research evidences that link the effectiveness of the internal auditor to improve the share price of an organization (Jensen, 1986).”

Next, I have the following mentioned in the TER:

What the student does here is downright unforgivable and so very shameful! When I first read that line I could not help myself from thinking that that could not be true. Who in his or her right mind would have linked internal audit and share price? Some time later with Allah's grace I was able to get from the web that very paper he referred to. At first I could not believe I got it, for I was just trying my luck. Anyway, as to be expected, no audit whatsoever is mentioned in the paper. What more on the supposed link between internal audit and entity's share price!

Jensen is one part of the famous Jensen \& Meckling of the classic 1976 paper on theory of the firm. Jensen (1986) is obviously a latter paper. But, it really does not matter as to whether it is 1976 or 1986 papers. Nobody would want to mess up with these guys' works. But here we are: a doctoral student of XXXX doing the nasty thing. Perhaps he has the view that no one will notice?

To be very honest, there are other things which appear under this section ... which pretty much scream "figments of one's imagination"! I feel sick reading them. On the other hand, there are also so laughable. I guess we really have here a case of tragicomedy, don't we?

Does not he know that there is so much (a limit) to what he can imagine? And in particular for a chapter on literature review for what is supposed to be a serious research study (which would lead to his getting the chance to use the title $D r$. in front of his name) he needs to point out one research work after another to back up his ideas. How absurd can he be?

The fact that the concerned research studies are nowhere to be found should only mean one thing for a serious student anywhere: that people much, much smarter and/or who work much harder than him or her have found a long time ago that what he or she now consider to be original ideas (such as the one here of the supposed link between internal audit and corporate financial performance) are mere hogwash! Surely a person does not need to have the brain of an Einstein (or the diligence of Azham) to figure this out? But maybe it is not the case of a brain size or quality. Instead, it is the case of nothing more than one's bloated ego?

It is perhaps worth knowing that related to this matter of falsifying research findings of others by the student, I have later pointed out on top of page 11 of the TER that upon reading the rest of the thesis there appeared to be several cases of possible falsification of other people's research other than that of Jensen (1986). Next, I have this stated out:

But I really could not find the time to locate the papers concerned so that I could go through them. For at least two of these possible cases I would also have to go through a lot of difficulty in doing so since they are unpublished PhD theses!

Right after these remarks, I pointed out in close to 300 words the apparent efforts by the student to mislead as found in page 41 of the thesis. I next ended my diatribe by saying the 
following on page 11 of the TER:

Having said all that which concerns other possible cases of research falsification, the case of Jensen (1986) alone should be sufficient to cause much rage among those who is concerned with the idea of researchers upholding research integrity. So, it was during the second reading occasion (mentioned at the beginning of this report) that I nearly went back to the concerned party in XXXX to say that I am no longer interested to be the examiner due to my distrust of the integrity of the research work. As we all know I did not do that. Instead, I went on to read the rest of the thesis to the end - and I had found other possible cases of fabrication! This was as I expected to be the case.

Now that that has been stated I can move on to the second thing: I do not believe anyone in his or her right mind can consider this lack of integrity in a $\mathrm{PhD}$ thesis to be of minor importance. A lot is at stake here. Among them is the XXXX's reputation. Can one imagine what the public would say if this shameful practice in research were allowed to go uncorrected? On my part, as far as I am concerned, I certainly do not want my name to be associated with the thesis in any form! So, that is why in my view this thesis can never be allowed to get anymore than a resubmission.

- Failing to provide clarity in several sections of the thesis: abstract, literature review, theoretical framework and conclusions

Early on, on top of page 12 of the TER, I mentioned that the discussion on the lack of clarity for theoretical framework and conclusions takes place in the latter part of the TER. As for that of the abstract, I mentioned that it had already taken place earlier under the heading incomprehensible English. When it concerns the literature review section of the thesis, I discussed the lack of clarity in three medium size paragraphs for passages found on page 41 and page 44. I had also mentioned the fact that no further discussion is needed for the same section of the thesis since this had already taken place earlier under the heading "Failing to substantiate remarks made" and "Ideas flow horribly / lack of coherence".

\section{- The horrible theoretical framework chapter!}

I began my diatribe in regard to the theoretical framework chapter of the thesis by saying the following found down below page 12 of the TER:

In terms of the total number of pages alone which is over 60 pages (pp. 46-107), this chapter is down right horrible. But there are other reasons for making it an appalling chapter able to bring so much pain to the readers.

Following these remarks, I detailed out in just over 1,800 words or in close to four pages of the TER the horror upon horror found in the theoretical framework chapter. The first horrific example mentioned is concerned with the one paragraph conclusion section on page 107 that is comprised of among others two sentences which have annoyed me to no end. Why? As I put it on top of page 13 of the TER: 
... they contain words I have never seen before used by anyone on a scholarly pursuit.

The following are the two sentences: "The present study clearly demonstrates the linkages between the variables ..."; "The present theoretical framework serves as another great contribution to the existing limited literature as well as guidance to promote more research in the ...."

And my comment on these sentences which appeared on page 13 of the TER:

The use of the word "clearly" is not appropriate. It is not for the student to judge his own work as to whether it is clear or not. But this writing sin on his part pales in comparison to the one which one may find in the latter sentence where he used the word "great" to describe his so called contribution to the literature. Why? Simply because as far as I am concerned that so called "great contribution" of his is nothing more than a miserable contribution of his!

As for the other weaknesses of the theoretical framework chapter of the thesis, they include the following four (which for the purpose of the TER is elaborated rather well but which is not done here at all):

$\checkmark$ Certain parts of the chapter are comprised of so many unnecessary pages. A good example of those which may be summarised in the form of a table is 3.1.1 to 3.1.6 (pp. 46-51). Some others should not have more than one or two lines or at most a paragraph to direct readers to the relevant publications. A very good example is section 3.6 on differences between stewardship and agency theories and its sub sections (pp. 86-95).

And the failure to be concise, I mentioned, has led to a total of three undesirable outcomes. For the first of these, I mentioned on the same page 13 of the TER the following:

Producing excessive number of pages for a single chapter - I have never seen before even when the theses are associated with world class universities such as Manchester that the theoretical framework chapter could have more than a few pages!

As for the second outcome, I wrote:

Repeating what others earlier have written to the point that it appears that in some places I could not help thinking that plagiarism has taken place! (How do I get to suspect such? Simply by the fact that for some of the concerned pages the English is so smooth in comparison to other pages where I can find so many faults with the English!)

$\checkmark$ The main parts of the chapter feel as if they are clobbered together with little interest in seeing that they flow nicely from beginning to end.

Related to this, on page 14 of the TER, I mentioned among others the following:

Should not the discussion on agency and stewardship theories come before anything else? Why does one have to get to read the following unequivocal line concerning the role of the two theories on page 105 which is the third last page of the chapter?

Too many pages allocated to the discussion of the agency and stewardship 
theories. As it is, these two topics combined have taken close to twenty pages of the chapter (pp. 69-86)! And this takes place when close to ten more pages (pp. 86-95) which is concerned with the discussion on the differences between the two theories are not taken into consideration.

In trying to make sense of this, I mentioned down below page 14 of the TER:

Why on earth the student wants to produce so many pages on these theories and their differences? Pray tell? It is not like he on his own build these things from scratch! Or, could it be that that is the impression he wants to give to the readers? Recall the word "great" which he used in the concluding section of the chapter and which I raised earlier. If that is the case, it is then down right pathetic. It is also so laughable if not for the fact that it is pure pain to have to read all this plus all those XXX in one single chapter of a thesis that is comprised of more than a few chapters!

What makes this effort so much more tragicomedy is that in the later part of the thesis the student goes out of his way to condemn these theories for the fact they are not able to explain his findings or something! Can one imagine this happening after having produced excessive number of pages on these theories and their differences? Trust me, that is just so bizarre! I will have more on this later.

Failure in several sections in the latter part of the chapter to write down the literature referred to.

In regard to this point, I pointed out the following which appeared on page 15 of the TER:

What is so out of this world in this effort of neglecting the references is that these sections of the chapter are concerned with the idea of theoretical support on the variable relationship. In other words, the sections concerned are supposed to be the gist of the chapter and which could very easily have the research studies mentioned earlier in the so called literature review chapter (which happens to be the chapter preceding the current chapter on theoretical framework) included in the discussion. Among those which are in dire need for references cited include the following two sections: section 3.7.1 where after almost three pages of writing that one can finally find one single work mentioned (p. 97); section 3.7.2 that is comprised of several pages (pp. 98-102) have only one single reference sited.

Having discussed all six examples of weaknesses of the theoretical framework chapter, I mentioned down below page 16 of the TER the following:

All in all, this chapter is quite an intolerable piece. Also, it reflects very badly on those parties responsible for its production. It appears that there is very little understanding of what a theoretical chapter is supposed to be. It is a pathetic effort which I hope and pray the like of which I shall never ever get the chance to see for the rest of my life! There is no other way of putting it: I am furious, sad and ashamed that a theoretical framework chapter of this kind can actually appear as part of a submitted $\mathrm{PhD}$ thesis.

In ending the discussion over the horrible theoretical framework chapter, there was the elaboration provided on a number of important issues which earlier had not been fully 
explored. Hence, it is in this later part of my diatribe on the theoretical framework chapter of the thesis that I was able to pinpoint what appears to me to be the most serious deficiency of the $\mathrm{PhD}$ - which is in having quite ill fitting theoretical foundation for the work. On page 17 of the TER, I stated out following:

I have a very strong feeling that the difficulty placed on the path of those reading this chapter and for that matter the thesis as a whole is concerned with the flimsy theoretical foundation of the research study. When there are hardly studies around associating XXX with XXX what else can actually be done other than speculating to no end? This is a good lesson for all including myself: choose an area of research where others have done some work in. Yes, it is important for a $\mathrm{PhD}$ work to be original or able to advance knowledge. But, it does not mean that a student could embark on something which is pretty much devoid of some respectable theoretical foundation! Has not it come across one's mind that surely the westerners who are much more advanced than the easterners especially those from developing countries such as Malaysia in so many ways including scientific research would have been concerned with the subject matter of the current $\mathrm{PhD}$ thesis if indeed it is worth believing or speculating on their part that there is a direct connection between XXX and XXX? Who on earth do we think we are vis-a-vis them? We must have bought hook, line and sinker that Malaysia Boleh slogan? Do we? Shameful, shameful, shameful!

With flimsy theoretical foundation, I next pointed out that it is of no surprise to find that even the one who proposed it has failed to accept it! As I wrote on page 18 of the TER:

Needless to say, as far as I am concerned, it is mind boggling to say the least for the student to have chosen certain theories forming the theoretical framework of his or her work but later turn his or her back on them with the accusation that there are not good or complete enough! Hence, I would like to venture the idea that there is here the case of failing to appreciate the meaning of the term theoretical framework of a scientific research. This very idea may in turn be connected to this bigger idea regarding the parties responsible for the writing of the thesis: that there is little appreciation on the proper manner of doing scientific research and in particular in the writing out of that research. It is as if the attitude held revolves around the idea that "who cares about the proper way when I know what I am doing!"

\section{- Research design and instrument development chapters}

At the beginning of this section of the TER which appeared on top of page 19, I wrote among others the following:

There are several places in the two chapters where I cannot avoid from asking myself the following question: what really is going on here?

That appears to be the right approach since numerous parts of the two chapters examined are affected with one problem or another which could lead to much confusion on the part of the reader. The following includes a number of these parts (which in the TER are elaborated rather well but which are not done here):

$\checkmark$ In the short one paragraph introductory section of the research design chapter, 
it is mentioned the various sections of the chapter. But then right after it there is a section with the heading "Summary of Hypotheses" which is not among those mentioned to be forming the chapter!

Right after these remarks, I wrote the following:

My take on what is going on is simply this: the student as I said at the end of the previous section on the horrible theoretical framework chapter has failed to know what he is doing! He is lost. He is in the dark. He needs help! In writing a thesis, a student is never supposed to do whatever he or she feels like doing. But in this thesis, time and again, the picture provided is that the student has been given the license to do whatever he wants. How does it get to be this way? Where are the people who are supposed to be interested in what he is doing? Hello?

I have a very strong feeling that this section 4.1 on hypotheses summary belongs elsewhere. In case it is insisted to be in chapter 4 efforts must take place to tie it up with the rest of the section! The issue here is that by having it dumped together with the rest leads to an incoherent look for the chapter.

In the one paragraph concluding section of the research design chapter ( $\mathrm{p}$. 129), the following is stated: "A careful consideration was made to ensure that this study was able to achieve the highest response rate." But in at least two important places in that very chapter the picture one get is the exact opposite. One of these two is concerned with the paragraph in the middle on page 114 where the following is stated: "Initially, the researcher planned to wait at each company in ensuring that each executive completed the questionnaires on the same day. Unfortunately, most of the internal audit executives from each of the companies were not in their office."

Hence, my comment which appeared on page 19 of the TER:

Does not he know in advance that these executives would not be around when he arrive at the companies' premises? So, where is that "careful consideration ..." now?

The atrocious writing of various parts of the two chapters including the one appearing as section 5.2.1 over the structure of the instruments.

In regard to section 5.2.1 in particular, I wrote on page 21 of the TER the following:

There are three paragraphs in total which begins on page 145 and ends on page 146. A reader would have a hard time to follow what is being described since the discussion jumped from one part of an instrument to another part of another instrument and next come back to the former instrument for another part of it and so on and so forth. It is really a pain to understand what is going on even when there are two figures on page 145 which is supposed to portray neatly the so called structure of the two questionnaire instruments!

I believe it would be of help if the first two lines on top of page 146 be separated from the rest in the paragraph. Those two lines should have been part of the previous paragraph on page 145 . 


\section{Ml Macrothink}

International Journal of Accounting and Financial Reporting

ISSN 2162-3082

2012, Vol. 2, No. 1

It would also be of help if the third and last paragraph is reconstructed. What on earth does the following mean? "The final part of the instrument comprises ..." Which instrument? The first or the second instruments discussed? If one were to look at the figures appeared in the previous page, it would be the first instrument discussed. But then, believe it or not, the rest of that sentence has the following mentioned which really makes everything very confusing! ... Is the student saying the two open-ended questions are concerned with those mentioned after the comma? Or, are those appeared after the comma concerned with some other open-ended questions for the other questionnaire instrument?

A question that I would like to raise is this: what can explain the failure of the student to write clearly for a very important section of the thesis which is concerned with the questionnaire instruments that he must have spent a long time developing? Pray tell.

$\checkmark$ On an assessment of the instruments reliability in the instrument development chapter, it is mentioned on page 148 that it was executed with assistance coming from students doing industrial attachment in various entities. Next, it is stated: The students served as agents for distributing the research instruments ... The diverse location of the students' attachments helped in satisfying the assumption of random sampling."

My comment related to this which appeared down below page 21 of the TER is as follow:

Am I reading this correctly? Random sampling? What is random sampling? Does the diversity of locations he writes about fit in with the meaning of random sampling? What is going on? To me it is more convenient sampling than anything else!

From the very beginning of the thesis and up to the section 5.2.3 of the instrument development chapter, the student never fails in saying that there exist two research instruments for the study. But in section 5.2.4, there is now a total of four instruments mentioned! As he wrote on page 152 of the thesis: "As there were four separate instruments ...."

Hence, my comment which appeared on top of page 22 of the TER:

Why up to now the reluctance of saying the presence of exactly four research instruments?

$\checkmark$ There is a missing page 150 .

And, my comment on this unforgivable act of the student is as follow which also appeared on top of page 22 of the TER:

How could this be possible? Is this one of those things which would lead a person to say "To err is human"? Or, is this just one of the so many things I have found in this thesis which screams (coming from the student): I can't be bothered! Unbelievable.

\section{- Results and interpretation chapter}

For a work which is supposed to have merited nothing more than a resubmission, it is perhaps of no surprise to find the following mentioned down below page 22 of the TER: 
More than any other chapters of the thesis this second to the last chapter has appeared to have laid bare all the worst problems with the thesis. Hence, more than any other chapters of the thesis, these problems scream for resubmission.

Among the issues raised in this section of the TER, they include the following:

In the one paragraph concluding section of the chapter there is the following: "This chapter provided the results of the statistical analysis .... In addition, this chapter also discussed the implication of the results to the literature. The next chapter will discuss the managerial implications of the results..."

As for my comment on these remarks, it includes among others the following two consecutive paragraphs which appeared on page 23 of the TER:

There is perhaps nothing wrong with the first half of those quoted lines. The problem is really with the second half. That "next chapter" mentioned by the student is titled "conclusion and recommendations". The word "conclusion" has never meant as far as I am concerned limited to the discussion of "managerial implications of the results ..." Why on earth the student chooses to do it differently to others before him? In case he wants to be unique or something, I suggest he has that chapter renamed to "managerial implications and recommendations" or something! Why opt to be unconventional but still stick to the same heading that other people use for the very last chapter of a thesis? Is this just one more in a long series of actions I have found in the thesis which may be likened to the sleight of hands of a magician?

One cannot be faulted for raising the question as what is the intention behind such actions. Allow me to suggest one reason for doing it this way for the last chapter of the thesis: to avoid making it very clear to all and sundry that the study has come out with findings which include those that are in the first place largely expected by many but not by the student! ... In short, I believe that by choosing to be unconventional in the last chapter of the thesis the student is able to avoid saying clearly that the study has started out with (largely) nothing of significance and has ended up with findings which are (largely) nothing of significance. A few years of work down the drain! But there is no need to shed tears. There should have been early on a need to understand that to embark on something original or to advance knowledge in a $\mathrm{PhD}$ pursuit one needs to see what others have done. A student in short needs to make sure that there is around a significant number of research studies to provide the theoretical guidance and empirical support to his or her work. One can readily see that that is not found for the present study. So, so sad!

Starting from page 160 and which goes on to the next few pages, there is the mentioning of a publication (XXX) whose findings are compared to those of the $\mathrm{PhD}$. To my knowledge, this work has failed to be discussed anywhere earlier in the thesis. Should not the student make the effort to discuss it prior to this chapter? And if for some reason that that is not appropriate, why the failure to discuss the paper fully early on in the chapter prior to have it mentioned in so many other pages later on? So, at the end of section 6.2.3 on page 160 , one is merely told the following: “... The results is consistent with 
the one reported by XXX with only two factors." What?

It is notable that the following was what I wrote next which appeared on page 24 of the TER:

(Actually, I am very much aware that XXX and the other one which is XXX which I raised earlier in the report are two among many listed at the beginning of the thesis under the heading publications and awards. Hence, these papers are the outcome of the $\mathrm{PhD}$ just like the thesis. And yet their findings are treated as if they are the results of totally different studies altogether to the point that the findings for one of these two papers can be used to support the findings discussed in the thesis! What is going on? Pray tell.)

$\checkmark$ Page 184 is placed right after - instead of just before - page 185 .

$\checkmark$ The nightmare within a nightmare that is section 6.4 of the thesis. (It is notable that similar thing is said on the related section 6.5.1 of the thesis and which came under section 10.8 of the TER.)

As I wrote on page 26 of the TER, section 6.4 has given evidence to what a nightmare this thesis is. I also mentioned that it would not have come to this if only the student is more honest in coming out with his or her theoretical framework. Next, I have the following mentioned:

How should I begin? Perhaps I should start by saying this: recall what I wrote for the following parts of this report: section 8.7 (agency and stewardship theories elaborated to the extreme); section 8.5 (lacking references to support variable relationships); and section 6.1 (falsifying research findings of others).

Because of these debilitating weaknesses found in the earlier chapters of the thesis, later in the last few pages of section 6.4 of the thesis, one cannot fail to find how miserable the student has become in explaining his one significant finding in a sea of insignificant findings! It is really quite sad.

Specifically, the misery he undergoes in trying to connect his research findings with his shaky theoretical framework appears to have taken place in several pages starting from the top paragraph on page 186. This goes on to the very end of section 6.4 on page 189 .

Following these remarks, my diatribe on what went on in section 6.4 of the thesis took close to 2500 words or six pages of writing in the TER! (This may be compared to that for section 6.5.1 of the thesis mentioned above which took over 1,500 words or three pages of writing in the TER.)

\section{Confusion and more confusion coming from section 6.5.1.}

In the TER, I came out with mere three examples of confusion. There were so many others which I decided not to describe. As I wrote on page 33 of the TER:

In the next few paragraphs beginning with the one down below page 194, the confusion continues unabated! If I were to point out which parts are filled with confusion marks, I may never be able to complete this report within the next few days. (Note: Today is last Sunday of 


\section{MInstitute Macrothink $_{\text {Int }}$}

International Journal of Accounting and Financial Reporting

ISSN 2162-3082

2012, Vol. 2, No. 1

the month. So, I have been trying to complete this report for three weeks already. Surely I am not expected to spend another three weeks on this thing? Already I am emailed that the oral exam has been fixed on the $14^{\text {th }}$ of next month!)

Suffice it for me to say that with the three cases above plus others which may be found in the few pages following the last example raised in 10.7.3, the student has never failed to confound me as to the low level of his writing skills - and his total disregard to the need to have his readers to be provided with as little difficulty as possible in following his line of thought. It is just down right disgusting! And what makes it more irritating is that deep inside me I believe that it is the latter more than the former which has greatly responsible to the problems I have found in this section 6.5.1 of the thesis - and for that matter for the similar and other problems I found in the rest of the thesis which this report is concerned with.

I could make that conclusion since there are several places in the thesis which he has shown the ability to write properly and where he appears to be concerned with quality output. A good example of the latter is the two research instruments where he goes through one step after another to get them to be "just right"!

\section{- The conclusion and recommendations chapter}

In the TER, my comment for the final chapter of the thesis took roughly 3,000 words or five and a half pages of writing. I began by saying the following on page 37 and which continues to page 38 of the TER:

As I mentioned early on in this report, there were in total three separate occasions where I spent time reading different parts of the thesis. This very last chapter was one of the two chapters I read on the first reading occasion. I had also read it again on the third and last reading occasion.

The first time I read it I was totally floored by its lack of clarity, terrible English and plain stupidity! I was in short not impressed at all. I could even say that I was furious by how bad a $\mathrm{PhD}$ could be when the country can hardly afford such an effort considering the fact that it is these days all systems go in ensuring Malaysia becoming a centre of excellence in education. I believe that was when I first thought of rejecting the appointment to be the thesis' examiner. That idea had later strengthened in the middle of reading the horrible sixty page theoretical framework which took place in the second reading occasion.

Just now in order to write for this very section of the report I had to go back to read it. Again I felt the rage inside me! So, it appears that even after having spent more than three weeks writing this report and earlier spending several days over a period of several months to read the chapters prior to this very last chapter, I am still the same furious person vis a vis it. To have people who read this to understand this rage, I hereby would like to share several passages - among many - of the chapter which I found most annoying for one reason or another.

Since I have totally had it up to my nose with the nonsense appearing on the pages of this chapter (I really feel the urge to throw up!), there are those below which I purposely fail to 


\section{MInstitute Macrothink $^{m}$}

International Journal of Accounting and Financial Reporting

ISSN 2162-3082

2012, Vol. 2, No. 1

detail out as to what exactly is wrong with them. You who read them can decide for yourself! (By the way, for some of these passages, there may be more than one problem to be found. The ones I raise are those I believe to be most awful in comparison to the rest!)

Later on page 39 of the TER, after having listed and discussed nine dreadful passages found in the chapter, I have the following mentioned:

Lest those reading this section of the report get the funny idea that this chapter's problems purely revolve around English and/or lack of clarity on certain passages (which may actually be due to the deep seated desire to mislead?), do check on the following three items which can provide the assurance that that cannot be more further from the truth! ... All in all, these items provide additional evidence that the thesis is asking very hard for a resubmission!

Following these remarks, this section of the TER had detailed out each of the three items: the first is concerned with the so called research instruments developed for the study; the second concerns what appears to be the real but pathetic motivation of the research which up to this chapter has never been made clear of; and the third is concerned with the norms in thesis writing. All three may indeed be labelled items of deficiency.

Among the three items of deficiency, the first is quite strange since it was the student himself who went out of his way in disclosing. As for the second deficiency, the student is most probably unaware that what he divulged had actually formed a devastating account on the real motivation of the study that originated from made up arguments of those practicing in the field. As for the third deficiency, a discerning reader of the thesis would without much difficulty detect it. And, it is the one which I believe many may find one additional lesson to learn. So, note the following which appeared on down page 42 and which continued to top page 43 of the TER:

There are so many cases throughout the thesis where the impression I have got is that the student is a great scholar already who needless to say knows exactly what he is doing. Hence, norms in thesis writing are not for him to abide with! In the final chapter of the thesis, this is well depicted by the fact that there is no section on the study's limitations. Instead, the section appears in the very first chapter of the thesis. Also, the section on the significance of the study should have been included in the first chapter. Instead, it appears in the very last chapter. By ignoring the thesis writing norms over and over again from the very first chapter to the last one, the student has made the thesis to be such a pain to read. As an examiner, I am not convinced that he has any good reason for disregarding these norms. In fact, I view the breaking away from the norms to be related to the effort to be less than truthful in the conduct of the thesis writing and for that matter the $\mathrm{PhD}$.

Really, if he is able to follow the exact protocol in developing not one but two research instruments which I am pretty sure has consumed quite a lot of time and energy and whatever else from him, surely it is within him to get his writing done properly? The outcome of not doing it right should be pretty obvious: that he has not yet reached the standard to have the $\mathrm{PhD}$ attached to his name and that he has to make it right the next time he goes for the $\mathrm{PhD}$ ! It is as simple as that - though it has certainly taken me a month and close to fifty pages of 
writing to get to the point of saying it!

All in all, it may be deduced that the failure to write in a consistent manner and the written English goes haywire are genuine problems of writing. But, for many other problems such as failing to substantiate remarks, lacking of coherence and lacking of clarity, these could probably just be the means to hide the more deep seated problems found with the $\mathrm{PhD}$. Such deep seated problems as mentioned earlier are concerned with fundamental issues of scholarly research. They include areas such as the motivation of the study, the theoretical framework, the research instruments and last but certainly not the least the data collected and analyzed.

For the first two of these deep seated problems, they may very well be responsible for some of the writing problems such as the lack of coherence, the lack of clarity and the falsification of other people's research. In the final analysis, however, it is hard for anyone (other than the student) to know the truth. But, if it is indeed the truth, this shows the importance of a $\mathrm{PhD}$ work and for that matter any other type of research study to have proper and clear research motivation which is supported by an acceptable and clear cut theoretical framework.

In the next section of the paper, there is the laying out of the various standards used to judge a $\mathrm{PhD}$ thesis coming from 16 institutions overseas plus one which is formed by a network of institutions. By having these standards identified, a comparison may next be made with the specific problems of the thesis mentioned earlier. It is hoped that by bringing the international perspective into the picture, the effort may help interested parties to have better understanding of what exactly is lacking with the thesis and for that matter any other thesis to be examined.

\section{International Standards}

The university in which the student whose $\mathrm{PhD}$ thesis is examined had stated in a document received that the post graduate examination is to be conducted at a level that is equal to the one found in institutions operating at the international level. No definition is however provided as to what this means. Hence, some strenuous efforts have taken place over a period of several days in order to look for the answer from several hundred websites. Next, there is a selection of several websites considered to have brought out the most revealing and helpful criteria that a $\mathrm{PhD}$ thesis should be judged against. The concerned websites are presented next in alphabetical order:

Atlantic Veterinary College of the University of Prince Edward Island's Graduate Program Guidelines (www.upei.ca/avc/files/avc/GradProgGuidelines.pdf):

- Clarity (organization, conciseness, style)

- Quality of, and student contribution to, the Research (design, execution, interpretation)

- Significance of Research 


\section{Macrothink}

International Journal of Accounting and Financial Reporting

ISSN 2162-3082 2012, Vol. 2, No. 1

Australian Council of Deans and Directors of Graduate Studies' Framework for Best Practice in Doctoral Examination in Australia (www.ddogs.edu.au/download/85503575):

- value of original contribution to knowledge in the field: its value to other researchers, originality, publishability, applicability, and (potential) impact;

- engagement with the literature and the work of others;

- grasp of methodology;

- capacity for independent, critical thinking;

- coherence of research program, its arguments and conclusions;

- quality of presentation.

$\begin{array}{lllll}\text { Avondale } & \text { College's } & \text { Thesis } & \text { Examination } & \text { Guidelines }\end{array}$ (www.avondale.edu.au/information::Policies/display/?s=MTc2):

- An original contribution to knowledge;

- Significance in the substance of the thesis in relation to the field in which the thesis is located;

- A high level of scholarship and quality;

- Good sequence and scholarly writing for a print thesis, or an equivalent standard acceptable to the discipline for a non-print thesis or portfolio;

- Extensive theoretical and substantive knowledge of the research topic and the associated literatures it encompasses;

- Clear and methodical thinking and a sustained cohesive line of argument for a lengthy work;

- Internal consistency between the research topic and appropriate analytical techniques;

- Presentation of the data in a succinct form for peer review, substantial analysis that draws meaning from the data, and the communication of the results;

- Implications for practice are drawn from the results of the study.

Chalmers University of Technology's PhD Degree Examination (www.chalmers.se/en/education/doctoral-programmes/you-are-a-doctoral-student/phd-degree -examination/Pages/default.aspx):

- The content must state clearly the problems that are addressed, in which scientific/technical context they are included and how this is delimited in the thesis.

- The methods used to solve the problem must be justified, described and evaluated.

- A comprehensive examination and evaluation of the literature within the area must be presented. 


\section{Macrothink}

International Journal of Accounting and Financial Reporting

- The results obtained must be reported together with conclusions and a critical examination/valuation of the individual's own results in relation to what has been published in international literature.

- Possible proposals for work in the future.

Durham

University's

Transition

to

PhD

(www.dur.ac.uk/cs.internal/researchpg/handbook/trans_to_phd/):

- A clear concise abstract which spells out the problem, its importance, the method of solution, and the results achieved. The original contribution must be identified. Note that a good criterion for an original contribution is "how will my results be used by others working in the field?"

- A first chapter setting the scene. An overview of the field and the problem area, and an amplification of the original contribution and its significance.

- Literature survey. Examiners will clearly look for references to the latest work, including conference proceedings. They will also look to ensure that all the key work in the area has been cited (a popular question at the viva is "which are the most important 3 papers in this field?"). However it is no use just listing the work and producing a taxonomy - this is necessary but not sufficient. The candidate must evaluate the significance of work, and show clearly that a mature critical viewpoint has been developed through a deep understanding of the field. For example, on a thesis on testing, it would be important to consider all the various different testing techniques, and to provide a way of categorizing them. This is not enough. The thesis must present an evaluation of this work, with a strong critical approach which comes from a deep theoretical and practical knowledge of the area.

Finally, the candidate must show that he or she is building on other people's shoulders - not their toes.

Note that it may be insufficient to read about an idea - it may be appropriate to contact or visit the researcher, or obtain a copy of the software and actually try it.

\section{Graduate Research School of the Massey University's Guidelines for Examiners Thesis Examination \\ Report}

(www.massey.ac.nz/massey/fms/Research/Graduate\%20Research\%20School/Documents/Ad ministration\%20forms/DRC6_1\%20-\%20V5\%2026_03_07.pdf):

- the candidate shows familiarity with, and understanding of, relevant literature

- the thesis provides a sufficiently comprehensive study of the topic

- the methods adopted are appropriate to the subject matter and are properly applied

- the research findings are suitably set out and accompanied by adequate exposition 


\section{Macrothink}

International Journal of Accounting and Financial Reporting

- the quality of English and general presentation is satisfactory

- the thesis as a whole makes an original contribution to the knowledge of the subject with which it deals, and the candidate understands the relationship of the thesis to the wider context of knowledge in which it belongs

\section{Lincoln University's PhD House Rules' Section 11:Thesis Examination (www.lincoln.ac.nz/Documents/1512_PhDsection11_s15378.pdf):}

- A PhD degree is designed to create new knowledge through original research. Therefore, candidates for $\mathrm{PhD}$ degrees must demonstrate originality, critical insight and a capacity to carry out independent research. A candidate has succeeded in this when the thesis can demonstrate to an examiner that, moving from the base of the declared aims and objectives, originality and insight are evident, that the results are original and represent new knowledge in the discipline, that this is done through excellence of presentation, that significant components of the work are publishable in refereed journals of standing, that sound statistical analyses have been carried out where appropriate, and that there has been good integration of the candidate's work with that in the literature.

- The thesis should contain a critical review of the literature on the subject. It should set out clearly the aims and the objectives of the research. The materials and methods used should be set out in sufficient detail so that the work could be repeated, where appropriate, by another person. Tables, graphs and figures should be well presented, accurate and concise and suitable techniques used to evaluate the results. Conclusions should be clear and precise. A final discussion should be included, covering previous work, the present results and future investigations.

- The thesis should contain information which contributes to the sum of knowledge or technical procedures on the subject studied and provides new understanding of the subject with which it deals.

- The thesis should be clear, accurate, cogent, and concise. It is to be free of typographical errors, errors of spelling or language construction.

- In scientific work, units of measure should conform to SI unless there are clear reasons for not doing so.

- The work should be suitably documented and citations correct in every detail. Although there is no prescribed standard method of setting out a reference list, the method adopted should be uniform throughout.

Melbourne School of Graduate Research of The University of Melbourne's PhD Thesis (www.gradresearch.unimelb.edu.au/current/phdhbk/thesis.html):

- does the candidate show sufficient familiarity with, and understanding and critical appraisal of, the relevant literature?

- does the thesis provide a sufficiently comprehensive investigation of the topic? 


\section{Macrothink}

International Journal of Accounting and Financial Reporting

ISSN 2162-3082

2012, Vol. 2, No. 1

- are the methods and techniques adopted appropriate to the subject matter and are they properly justified and applied?

- are the results suitably set out and accompanied by adequate exposition and interpretation?

- are conclusions and implications appropriately developed and clearly linked to the nature and content of the research framework and findings?

- has the research question(s) in fact been tested?

- is the literary quality and general presentation of the thesis of a suitably high standard?

- does the thesis as a whole constitute a substantive original contribution to knowledge in the subject area with which it deals?

...the thesis demonstrates authority in the candidate's field and shows evidence of command of knowledge in relevant fields

- it shows that the candidate has a thorough grasp of the appropriate methodological techniques and an awareness of their limitations

- it makes a distinct contribution to knowledge. Its contribution to knowledge rests on originality of approach and/or interpretation of the findings and, in some cases, the discovery of new facts

- it demonstrates an ability to communicate research findings effectively in the professional arena and in an international context

- it is a careful, rigorous and sustained piece of work demonstrating that a research "apprenticeship" is complete and the holder should be admitted to the community of scholars in the discipline.

Postgraduate Office of the Research and Regional Services Directorate of the Queen's University of Belfast's Guidelines for Examiners of Theses Submitted for the Degrees of PhD and Mphil (www.qub.ac.uk/cm/cms/docs/guide-PhD-MPhil.doc):

- makes a distinct contribution to knowledge

- affords evidence of originality as shown by the discovery of new facts, the development of new theory or insight or the exercise of independent critical powers

- contains an acceptable amount of original work by the candidate which is of publishable standard, either in the form of articles in appropriate refereed journals or as the basis of a book or research monograph which could meet the standards of an established academic publisher

- is written to a standard acceptable for academic and professional communication. 


\section{Macrothink}

International Journal of Accounting and Financial Reporting

ISSN 2162-3082

2012, Vol. 2, No. 1

Postgraduate Online Research Training of the Institute of Germanic and Romance Studies of the School of Advanced Study of the University of London's PhD Examination's Assessment Criteria (port.igrs.sas.ac.uk/vivaassess.htm):

\section{Assessment criteria concerning form}

- Clarity of presentation: the layout of your thesis must be as clear as its language and structure. It has to be as readable from the linguistic/stylistic point of view as it is from the organizational point of view. It has to be underpinned by effective cross-references, so that your examiners can easily find the parts (chapters, paragraphs or tables) they are most interested in. Your bibliography and footnote references should be free from structural and stylistic inconsistencies.

\section{Assessment criteria concerning methodology}

- Coherence: a PhD cannot simply be a cluster of considerations and analyses, however cogent and original. It has to reflect a coherent research process from the acquisition of its basic data to its final findings. The rationale behind your research must be clear and persuasive.

- Methods of enquiry: a PhD must not only be methodologically sound but also explicitly discuss the rationale behind it. The appropriateness of the method chosen is one of the qualifying points of any research and its adoption must be based on the explicit awareness of its advantages and disadvantages.

- Data (or textual) analysis: this constitutes one of the key points of any $\mathrm{PhD}$, since its outcome usually offers the most original contribution to the whole project. The criteria used in selecting data (or textual extracts), the method of enquiry and the results of each analysis must therefore be clear and consistent.

\section{Assessment criteria concerning contents}

- Review of relevant literature: no worthwhile piece of research can do without a first-hand knowledge of the relevant literature. This cannot be attested by a mere list of articles; you are supposed to compare and evaluate the most important contributions to your area, highlighting both their limits and merits.

- Research problem: your $\mathrm{PhD}$ should look like the solution to a research issue which had not been previously investigated, but which was clearly worthy of study; which may already have already identified, but which had not yet been solved. This issue should emerge naturally from your analysis of the current state of knowledge in your area.

- Contribution to knowledge: a $\mathrm{PhD}$ should not limit itself to demonstrating your knowledge of the discipline. It should also be a new contribution to it, a contribution worth becoming in turn part of the literature.

- Originality: it is the magic word of any $\mathrm{PhD}$. As difficult as it is to define 'originality', it certainly means that: the thesis you submit must be your own work; it has to reveal 
a proper degree of independent working; it has to include an original contribution to your field of study.

- Discussion of outcomes: no piece of research can be definitive. Real research proceeds by stages. Your thesis should reveal this awareness by placing your research in the context of current literature, on the one hand, and, on the other, by indicating which parts would be worthy of further investigation. Being prepared to discuss the limitations, in addition to the achievements, of your research will be equally appreciated.

Research Students Centre of the Queensland University of Technology's Report of $\begin{array}{llllll}\text { Examiner for } & \text { Award of } & \text { Philosophy }\end{array}$ (www.rsc.qut.edu.au/pdfs/examinations/PhD_Examiner_Documentation.pdf):

- Does the thesis meet the following criteria for the award of a PhD within the body of knowledge and understanding of the field of study with which it is concerned:

- originality of contribution

- significance of contribution

$\checkmark$ quality of work?

- Is the standard of literary presentation in the thesis satisfactory?

- Is the methodology applied in the candidate's research sufficiently effective and appropriate for the thesis topic and for a $\mathrm{PhD}$ ?

- Does the thesis reflect sufficient competence in the survey of literature and documentation of statements?

- Is the thesis suitable for publication as a book or in a learned journal:

$\checkmark$ in the form submitted

$\checkmark$ with modifications?

Schulich School of Music of McGill University's Thesis Preparation, Submission and Evaluation

(www.mcgill.ca/music/current-students/graduate/graduate-music-handbook/thesis-preparatio n-submission-and-evaluation):

- Evidence of originality and creativity.

- Resourcefulness, alertness to significance of findings.

- Diligence, care, technical skill in the research.

- Usefulness of the results to other workers in the field; value as a contribution to knowledge.

- Grasp of subject, powers of criticism and general adequacy in review of previous 
work.

- Quality of presentation (coherence, lucidity, grammar, style, freedom from typographical errors).

Swineburne University of Technology's Guidelines for Examination of a PhD (www.research.swinburne.edu.au/higher-degrees/documents/guidelines_for_phd_examinatio n.pdf):

- make an original contribution to knowledge in terms of the originality of the approach and/or findings;

- constitute a coherent and cogent argument that communicates the significant elements of the research in a professional context as well as within a national and/or an international context;

- demonstrate authority of the candidate within the given field(s) and indicate knowledge of related fields;

- show a firm grasp of the methodological aspects of the research, from overall approach to explicit techniques;

- demonstrate a high level of language use that is both professional and academic, as well as being free of typographical and grammatical errors;

- provide, where relevant, a high level of reproductive quality with respect to illustrative, graphic and other non-print text material;

- be a rigorous, sustained, logical and considered piece of work demonstrating that the candidate is ready to be admitted to the community of scholars within the discipline(s).

The University of Otago's Handbook for PhD Study (www.otago.ac.nz/study/phd/handbook/otago001862.pdf:

- Does the thesis comprise a coherent investigation of the chosen topic?

- Does the thesis deal with a topic of sufficient range and depth to meet the requirements of the degree?

- Does the thesis make an original contribution to knowledge in its field and contain material suitable for publication in an appropriate academic journal?

- Does the thesis meet internationally recognised standards for the conduct and presentation of research in the field?

- Does the thesis demonstrate both a thorough knowledge of the literature relevant to its subject and general field and the candidate's ability to exercise critical and analytical judgement of that literature?

- Does the thesis display mastery of appropriate methodology and/or theoretical 
material?

University College Dublin's Guidelines for PhD Examiners (www.ucd.ie/registry/assessment/staff_info/guidelines_for_PhD_examiners.pdf):

- The originality of the work described and the theories developed in the thesis;

- The candidate's familiarity with the published work of other authors in related areas;

- The candidate's ability to summarise the work of other authors and to synthesise a theoretical framework within which to position the work described in the thesis;

- The candidate's prose style should be appropriate to the discipline, but clear, simple, unambiguous writing, which is syntactically and grammatically correct, is required of all candidates;

- The methodology adopted by the candidate to address the research topic - Is it accurately and comprehensively described? Is it appropriate to the topic? Is the candidate aware of alternative methodologies which might have been employed?

- Is the candidate sensitive to any inherent weaknesses in the methodology? Where a novel method has been developed, has it been tested and calibrated appropriately?

- Experimental Design (where appropriate)

- Presentation of the results of the research. Are the results presented in a clear, accessible way? Are tables, figures or plates, where included, adequately annotated and correctly referenced in the text?

- Interpretation of Results: are the candidate's conclusions reasonable on the basis of the evidence presented? Has the significance of the results been fully appreciated by the candidate? Has the correct statistical analysis been employed (where appropriate) and justifiable conclusions arrived at? Have theories formulated on the basis of the results taken into account relevant findings published by other authors? Has the candidate identified any weaknesses or lacunae in the evidence adduced?

- The bibliography - is it comprehensive and up-to-date? Are references to the published literature annotated accurately and consistently in a recognised citation style?

- Presentation of the thesis - is it free of typographical and other errors?

University of Newcastle Upon Tyne's University Handbook for Examiners of Research Degrees

(www.ncl.ac.uk/students/progress/assets/documents/UniversityHandbookforExaminersofRD P09.pdf):

- Authentic

- Scholarly 


\section{Macrothink}

- Professional

- Well-structured, written and presented

- should show evidence that the subject has been studied with adequate industry and application

- demonstrates an ability to conduct original investigations and to test the ideas of the candidate and those of others

- shows that the candidate understands the relationship of the theme of his or her thesis to the wider field of knowledge

- exhibits substantial evidence of original scholarship

- contains material worthy of publication

\section{University of Oxford's Preparing Students for Examination} (www.learning.ox.ac.uk/rsv.php?page=320):

- that the candidate possesses a good knowledge of the particular field of learning within which the subject of the thesis falls;

- that the candidate has made a significant and substantial contribution in the particular field of learning within which the subject of the thesis falls;

- that the thesis is presented in a lucid and scholarly manner;

- that it merits the degree of Doctor of Philosophy; and

- that the candidate has presented a satisfactory abstract of the thesis.

In revealing the list above, note that certain criteria are shaded. The shaded criteria in contrast to those which are not shaded corresponds to some thesis' problems mentioned earlier. By comparing the shaded criteria and the identified problems of the concerned thesis, it is hoped that a better picture as to what is lacking in that $\mathrm{PhD}$ thesis may actually come about and which should lead to an improved understanding among many of what is expected of the so called $\mathrm{PhD}$ thesis of an international standard.

As an example, when comparison is made between the problems identified in the $\mathrm{PhD}$ thesis and the criteria which come under the Australian Council of Deans and Directors of Graduate Studies' Framework for Best Practice in Doctoral Examination in Australia (www.ddogs.edu.au/download/85503575), it may safely be deduced that the thesis has failed to meet up with the so called international standards. This is because the thesis has failed in all areas listed except perhaps on the grasp of methodology.

Specifically, with the presence of so many insignificant findings, the $\mathrm{PhD}$ work when judged against the first measure listed from the top would lead to the conclusion that it is of little value to other researchers and has little chance for publications. And with the failure to be honest and provide full disclosure in so many of the literature cited, surely there is nothing much which may be said on the next measure listed which concerns a thesis' engagement 
with the literature and the work of others. As for the capacity for independent and critical thinking criterion, surely little is found in the thesis when among others the real motivation for the study appeared to have come from arguments made by those practicing in the field who in all probability have nothing but financial reasons for arguing on the importance of the profession. Finally, against the last two criteria of coherence of its arguments and conclusions and of quality of presentation, the thesis has performed quite badly due among others to more than a few cases of lack of clarity and incomprehensible English.

\section{Discussion and Conclusions}

I have a hard time in looking out for what is of merits in the thesis. The idea that the research instruments may be considered the thesis' strength should now be forgotten when the student himself has brought doubt on their quality (see discussion in section 11:10 above). As for the thesis' weaknesses, they involve shoddy presentation (see for example discussion in sections 1, 2, 4 and 5), flawed theoretical framework (see for example discussion in sections 8.5 and 8.6) and deficit of integrity in the review and use of literature (see for example discussion in sections 6 and 7.2).

To reiterate what I have said repeatedly above, the thesis needs to go for resubmission which I do not believe can take place within a year. In my estimation, the student needs at least one and a half years in order to complete the work. If it is mere sloppy presentation covering issues such as lack of coherence and typographical, bibliographical and grammatical errors, the improvement may not need that much time. But in our case here is a thesis whose theoretical framework and the review and use of literature are in need for a major overhaul!

These two paragraphs appear in the final section of the TER that comes with the heading "Lessons for All". The first of the two is actually the first paragraph of that section of the TER. The other paragraph comes soon after. Between these two paragraphs, there is one long paragraph which contains the following remarks:

All in all, to borrow the remark I found in one of the web materials which I worked with for this report, the $\mathrm{PhD}$ thesis is far from being "a careful, rigorous and sustained piece of work demonstrating that a research 'apprenticeship' is complete and the holder is admitted to the community of scholars in the discipline."

That it had to come to this was and still is, I believe, a sad thing for everybody concerned. But a judgement had to be made - and it came about not in an easy manner but after a gruelling process of examination where the writing of the report alone took weeks to complete!

But all is not lost since as far as the external examiner is concerned there is the desire to turn the draining experience of examination into a positive one. And the way to go about doing it is to conduct a research in the field of $\mathrm{PhD}$ examination in the country. There is a need for such since to date there does not seem to be any published studies on local $\mathrm{PhD}$ examination found from the search of the internet. This is in contrast to the extensive studies done over the years in countries such as Britain and Australia. 


\section{MInstitute ${ }^{\text {Mank }}$}

International Journal of Accounting and Financial Reporting ISSN 2162-3082 2012, Vol. 2, No. 1

In the case of Australia, just to mention a few, they include Holbrook, Bourke, Lovat and Fairbairn (2008); Holbrook and Bourke (2004); Holbrook, Bourke, Lovat and Dally (2004); Mullins and Kiley (2002); Johnson (1997); and Pitkethly and Prosser (1995). As for Britain, they include Tinkler and Jackson (2004); Denicolo (2003); and Jackson and Tinkler (2001, 2000).

Aside from these and other studies on specific countries' $\mathrm{PhD}$ examination, there are even cross countries studies such as Noble (1994) for the USA, UK, Australia and Canada and Kouptsov (1994) for Europe found through the search of the internet. Hence, for the intended study or rather a series of study on PhD examination in the Malaysian context, these overseas studies may very well become the models to be followed. The ideas generated from such effort in the form of for example policy implications should then be able to help the country in strengthening the postgraduate programs at local higher institutions. And together with the rest of the efforts conducted by various other parties who aim for the same thing from both in and outside these institutions, huge benefits - both financial and non financial; tangible and non tangible; short and long terms; personal and national - should then come our way. InsyaAllah! Hence, hardly anymore cases of $\mathrm{PhD}$ thesis such as the one that led to the writing out of this paper? Let us all hope and work for the best!

\section{References}

AVC graduate program guidelines. (n.d.). Retrieved April 03, 2010, from Atlantic Veterinary College: http://www.upei.ca/avc/files/avc/GradProgGuidelines.pdf

Denicolo, P. (2003). Assessing the PhD: A constructive view of criteria. Quality Assurance in Education, 11(2), 84-91.

Framework for best practice in doctoral examination in Australia. (2005, August). Retrieved April 03, 2010, from The Australian Council of Deans and Directors of Graduate Studies: http://www.ddogs.edu.au/download/85503575

Guidelines for examiners - Thesis assessment report. (n.d.). Retrieved April 03, 2010, from Massey University Graduate Research School: http://www.massey.ac.nz/ massey/fms/Research/Graduate\%20Research\%20School/Documents/Administration\%20for ms/DRC6_1\%20-\%20V5\%2026_03_07.pdf

Guidelines for examiners of theses submitted for the degrees of PhD and Mphil. (n.d.). Retrieved April 03, 2010, from Queen's University Belfast Research and Regional Services Directorate Postgraduate Office: http://www.qub.ac.uk/cm/cms/docs/ guide-PhD-MPhil.doc

Guidelines for PhD examiners. (n.d.). Retrieved April 03, 2010, from University College Dublin: http://www.ucd.ie/registry/assessment/staff_info/guidelines_for_PhD_examiners.pdf

Holbrook, A., \& Bourke, S. (2004). An investigation of $\mathrm{PhD}$ examination outcome in Australia using a mixed method approach. Australian Journal of Educational \& Developmental Psychology. 4, 153-169.

Holbrook, A., Bourke, S., Lovat, T., \& Dally, K. (2004). Qualities and characteristics in the 
written reports of doctoral thesis examiners. Australian Journal of Educational \& Developmental Psychology, 4, 126-145.

Holbrook, A., Bourke, S., Lovat, T., \& Fairbairn, H. (2008). Consistency and inconsistency in $\mathrm{PhD}$ thesis examination. Australian Journal of Education, 52(1), 36-48.

Jackson, C., \& Tinkler, P. (2001). Back to basics: A consideration of the purpose of the PhD viva. Assessment \& Evaluation in Higher Education, 26(4), 355-366.

Jackson, C., \& Tinkler, P. (2000). The PhD examination: An exercise in community building and gate keeping? In I. McNay (ed) Higher Education and its Communities. Buckingham: Society for Research into Higher Education and Open University Press, 38-50.

Johnson, S. (1997). Examining the examiners: An analysis of examiners' reports on doctoral theses. Studies in Higher Education, 22(3), 333-347.

Kouptsov, O. (1994). The doctorate in the Europe region. CEPES UNESCO.

Mullins, G., \& Kiley, M. (2002). 'It's a PhD, not a nobel prize': How experienced examiners assess research theses. Studies in Higher Education, 27(4), 369-386.

Noble, K. (1994). Changing doctoral degrees - An international perspective. Buckingham England: Society for Research into Higher Education.

PhD degree examination. (n.d.). Retrieved April 03, 2010, from Chalmers: http://www.chalmers.se/en/education/doctoral-programmes/you-are-a-doctoral-student/phd-d egree-examination/Pages/default.aspx

PhD thesis. (n.d.). Retrieved April 03, 2010, from Melbourne School of Graduate Research: http://www.gradresearch.unimelb.edu.au/current/phdhbk/thesis.html

Pitkethly, A., \& Prosser, M. (1995) Examiners' comments on the international context of PhD theses. In C. McNaught \& K. Beattie (eds) Research into higher education: Dilemmas, directions and diversions. Melbourne: HERDSA, 129-36.

Preparing students for examination. (n.d.). Retrieved April 03, 2010, from Oxford Learning Institute: http://www.learning.ox.ac.uk/rsv.php?page=320

Report of examiner for award of doctor of philosophy. (n.d.). Retrieved April 03, 2010, from QUT Research Student Centre: http://www.rsc.qut.edu.au/pdfs/examinations/PhD_ Examiner_Documentation.pdf

Powell, S. \& Green, H. Assessing the doctorate and defending the thesis. (n.d.). Retrieved April 03, 2010, from http://www.postgraduatedirections.org.uk/Assessing DoctorateAndDefendingThesis.pdf

Tinkler, P., \& Jackson, C. (2000). Examining the doctorate: Institutional policy and the PhD examination process in Britain, Studies in Higher Education, 25(3), 167-180.

Tinkler, P., \& Jackson, C. (2004). The doctoral examination process: A handbook for students, examiners and supervisors. Maidenhead, England: Open University Press. 


\section{Macrothink}

International Journal of Accounting and Financial Reporting

ISSN 2162-3082 2012, Vol. 2, No. 1

Thesis examination. (n.d.). Retrieved April 03, 2010, from http://www.lincoln.ac.nz /Documents/1512_PhDsection11_s15378.pdf

Thesis examination guidelines. (n.d.). Retrieved April 03, 2010, from Avondale College: http://www.avondale. edu.au/information::Policies/display/?s=MTc2

Thesis preparation, submission, and evaluation. (n.d.). Retrieved April 03, 2010, from McGill

University: http://www.mcgill.ca/music/current-students/graduate/graduate-music-handbook/thesis-prepa ration-submission-and-evaluation

Transition to PhD - Reaching the standard. (n.d.). Retrieved April 03, 2010, from Durham University: http://www.dur.ac.uk/cs.internal/researchpg/handbook/ trans_to_phd/

University handbook for examiners of research degrees by theses. (n.d.). Retrieved April 03, 2010, from Newcastle University: http://www.ncl.ac.uk/students/progress/assets /documents/UniversityHandbookforExaminersofRDP09.pdf

What criteria will the examiners base their assessment on? (n.d.). Retrieved April 03, 2010, from http://port.igrs.sas.ac.uk/vivaassess.htm 